Ann. Zootech., I978, 27 (4), 47 I-494.

\title{
Lactosérum sec dans l'alimentation du Porc
}

\section{II. - Adaptation et conséquences sur la croissance et l'efficacité alimentaire $\left(^{*}\right)$}

\author{
C. FIVVRIER et A. AUMAITRE \\ avec la collaboration technique de Françoise HOULIER, Huguette BONDU-DEWUlf, \\ M. Marion et C. Daulotdet \\ Station de Recherches sur l'Élevage des Pores, \\ Centre national de Recherches zootechniques, I.N.R.A. \\ $7835^{\circ}$ Jouy-en-Josas (France)
}

\section{Résumé}

Dans une expérience portant sur 72 porcelets Large White sevrés à 35 jours, on a recherche l'influence de régime de sevrage comportant $5 \mathrm{p}$. Ioo de poudre de lait écrémé (lot I) ou bien Io p. Ioo et $20 \mathrm{p}$. Ioo de lactosérum doux (lots 2 et 3 ) sur l'utilisation ultérieure de régimes d'engraissement comprenant 0,30 ou $60 \mathrm{p}$. Ioo de poudre de lactosérum et I $8 \mathrm{p}$. Ioo de matières azotées totales (lots $\mathrm{D}, \mathrm{E}, \mathrm{F}$ ). Après $60 \mathrm{~kg}$ de poids vif, pour la moitié des animaux de chacun des lots précédents, le taux azoté a été réduit à i I p. roo (lots $A, B, C$ ). Après le sevrage, entre les poids vifs moyens de 8,8 et $2 \mathrm{I} \mathrm{kg}$, les meilleures performances ont été obtenues avec ro p. Ioo de lactosérum sec, 20 p. roo augmentant la dureté des granulés et les rendant peu appétibles pour le porcelet. Au cours de la période suivante, l'emploi de $30 \mathrm{p}$. I oo de lactosérum sec (E) a significativement amélioré les performances des porcs $(+30 \mathrm{p}$. I OO) tandis que les lots $\mathrm{D}$ et $\mathrm{F}$ donnaient des résultats équivalents. A $60 \mathrm{~kg}$ de poids vif aucun effet du régime de post sevrage n'apparaissait. La fourniture continue de lactose après le sevrage n'a donc pas amélioré l'utilisation ultérieure de fortes quantités dans le régime du porc en croissance. En période de finition les résultats des lots $\mathrm{A}$ et $\mathrm{B}$ d'une part, $\mathrm{D}$ et $\mathrm{E}$ de l'autre ont été équivalents alors que les lots $\mathrm{C}$ et $\mathrm{F}$, à $60 \mathrm{p}$. roo de lactosérum, présentaient une vitesse de croissance et une efficacité alimentaire médiocres $(-7 \mathrm{p}$. Ioo pour le lot $\mathrm{C}$ ) d'autant plus que le taux azoté était élevé (- Io p. Ioo pour le lot $\mathrm{F}$ ).

La supériorité de la vitesse de croissance des mâles castrés sur celle des femelles a été plus marquée dans les régimes témoins que dans ceux comportant du lactosérum. Les carcasses des femelles ont été plus maigres que celles des mâles castrés. La réduction d'adiposité a été également obtenue par l'augmentation des taux de lactosérum et par le maintien d'un taux protéique élevé pendant tout l'engraissement. Toutefois la différence de composition des carcasses entre femelles et mâles castrés était plus grande chez les animaux témoins que chez ceux recevant du lactosérum.

Ces résultats s'expliquent par la diminution de rendement énergétique lors de l'incorporation

(*) Une présentation partielle des résultats de cette expérience a été réalisée dans : FÉvrIER C., Aumaitre A., r 972 . Evolution de 1'utilisation du lactosérum dans les régimes de seviage précoce du porcelet et durant la période de croissance-finition. Journées Rech. Porcine en France, 4, 199-206, I.N.R.A.I.'T.P. éd., Paris. 
du lactose en grande proportion en période de finition. Les régimes contenant du lactosérum sec, notamment au taux le plus élevé, ont eu un effet diarrhéique important. Pour obtenir la meilleure valorisation, le lactosérum doit donc être utilisé en quantité modérée au cours de cette période ( $1 / 3$ de la ration) et complémenté de manière adéquate, sans excès, ni subcarence protéique, en tenant compte des besoins particuliers selon le sexe.

\section{Introduction}

Dans une expérience précédente (FÉvRIER, I978) il a été observé que le lactosérum sec est d'autant moins bien valorisé que son taux d'introduction dans la ration est plus élevé et le porc plus âgé. Cependant, les porcelets utilisés avaient été privés de lactose depuis le sevrage, pendant une durée de trois à quatre semaines, avant de recevoir le lactosérum sec. Or chez le rat, quelques auteurs ont montré qu'il pouvait $\mathrm{y}$ avoir une adaptation à l'hydrolyse enzymatique du lactose lorsque celui-ci était maintenu dans la ration (FISHER, I957; Bor,IN, MC KERN et Davis, I97I; Bozkowa et BARvox, I973); il en est semble-t-il de même chez le singe (WEN et al., I973).

Pour le porc, cette idée est encore communément répandue bien qu'à notre connaissance, il n'en existe pas de preuve expérimentale. La présente expérience avait donc pour but principal de tester la validité de cette hypothèse. Elle a également permis de préciser les modalités d'utilisation du lactosérum sec dans les aliments de sevrage du porcelet. Ce dérivé du lait présente en effet quelques avantages pour remplacer le lait écrémé dont le côtt est excessif pour des aliments de sevrage à cinq semaines. C'est une source de lactose, glucide bien valorisé par le porcelet (BECkER, UlLREY et Terrid., I954; Aherne et al., I969; SEVE, FÉvrier et Aumaitre, I975), et dont l'emploi peut avoir un effet favorable sur la digestion des protéines chez le jeune (SEWEI, et WEST, I965). Les protéines du lactosérum, bien que peu abondantes, ont une digestibilité élevée et un équilibre satisfaisant en acides aminés (PION et FAU CoNxEAU, I966). Elles sont donc bien utilisées par le porcelet (Kornegay, Thomas et Kramer, I974). Enfin, il ne faut pas négliger l'apport en vitamines du groupe $B$.

Il a été précédemment démontré (FÉVRIER, I978) que l'excès d'apport protéique est particulièrement défavorable à la croissance et à l'efficacité alimentaire chez le porc en période de finition, au delà de $60 \mathrm{~kg}$ de poids vif. Un dernier objectif a donc été de confirmer cet effet en ne modifiant la teneur en protéines de la ration que pendant la seule période de finition.

\section{Matériel et méthodes}

Les porcelets de race Large White, provenaient du troupeau expérimental de la Station. Trois couples constitués d'une femelle et d'un mâle castré ont été retenus dans I 3 portées de porcelets sevrés à 35 jours. Le plan expérimental est schématisé en figure $I$.

Entre le trente sixième jour et le poids vif minimum de Ig $\mathrm{kg}$, chaque couple a été logé en case danoise et affecté au hasard à l'un des aliment de sevrage (tabl. I) 


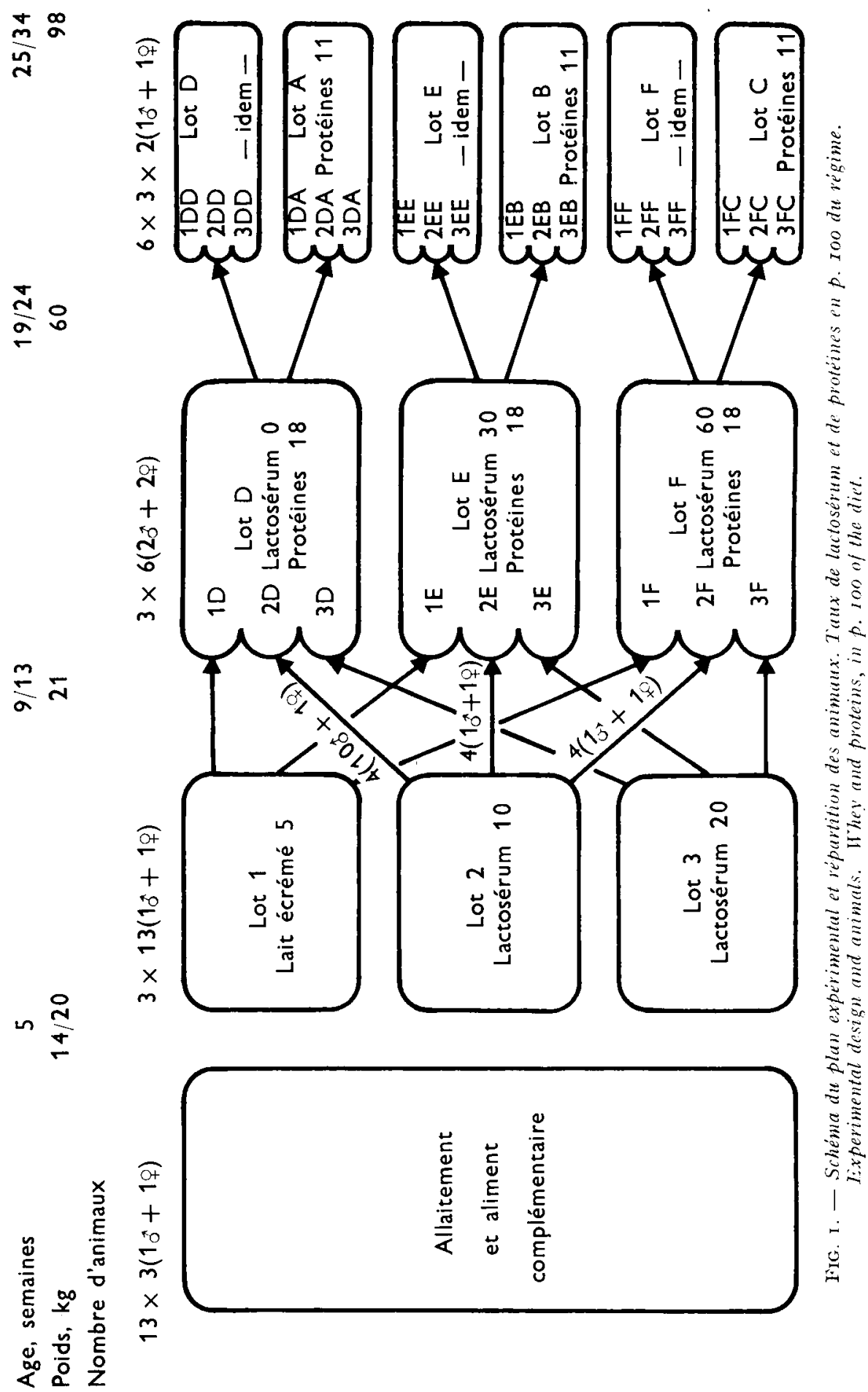




\section{TABLEAU I}

Composition des régimes de sevrage

Weaning diets composition

\begin{tabular}{|c|c|c|c|}
\hline Lot & $\begin{array}{c}\text { Lait écrémé sec } \\
5 \mathrm{p} \text {. Ioo }\end{array}$ & $\begin{array}{l}2 \\
\text { Lactoserum sec } \\
\text { lo p. I } 00\end{array}$ & $\begin{array}{c}3 \\
\text { Lactoserum sec } \\
20 \text { p. Ioo }\end{array}$ \\
\hline 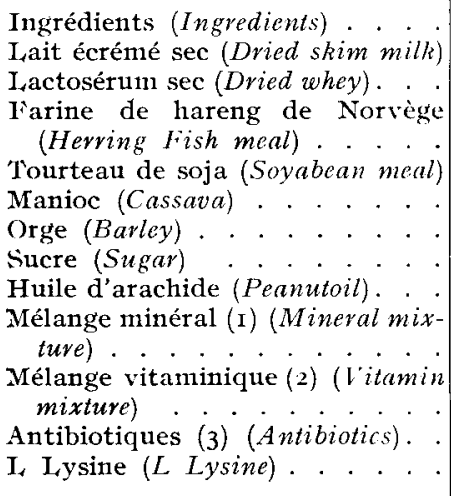 & $\begin{array}{c}6 \\
20 \\
30 \\
27 \\
5 \\
3 \\
2,5 \\
\text { I } \\
0,5 \\
-\end{array}$ & $\begin{array}{l}\text { I0 } \\
6 \\
20 \\
32 \\
20 \\
5 \\
3 \\
2,5 \\
\text { I } \\
0,5 \\
0,07\end{array}$ & $\begin{array}{l}\text { - } \\
\text { 60 } \\
20 \\
35 \\
10 \\
5 \\
3 \\
2,5 \\
\text { I } \\
0,5 \\
0,07\end{array}$ \\
\hline 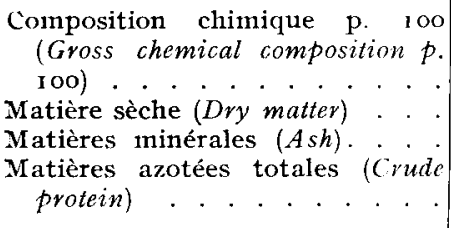 & $\begin{array}{l}92,3 \\
5,98 \\
\text { I } 7, \mathrm{I}\end{array}$ & $\begin{array}{l}93, \mathbf{I} \\
6,28 \\
\text { I } 7,6\end{array}$ & $\begin{array}{r}91,7 \\
5,98 \\
\text { I } 8,4\end{array}$ \\
\hline & Dried skim milk & Dried whey & Dried whey \\
\hline
\end{tabular}

(I) Mélange minéral ( $\mathrm{g}$ pour $100 \mathrm{~g}$ ) : carbonate de calcium : 22,8; carbonate de magnésium : Io; phosphate bicalcique : 40 ; chlorure de sodium : 25 ; carbonate de zinc: $\mathbf{I}$; sulfate ferreux $7 \mathrm{H}_{2} \mathrm{O} ; \mathrm{I}$, sulfate de manganèse $5 \mathrm{H}_{2} \mathrm{O}: 0, \mathrm{I}$; sulfate de cuivre $5 \mathrm{H}_{2} \mathrm{O}: 0$, o5; sulfate de cobalt $7 \mathrm{H}_{2} \mathrm{O}: 0,05$; iodure de potassium : 0,01 .

(2) Mélange vitaminique ( $g$ pour I ooo g) : panthothénate de calcium : 2,5; riboflavine : $\mathrm{I}$; acide ascorbique : $\mathrm{I}$; nicotinamide : 2 ; vitamine $\mathrm{B}_{12}(100000 \mathrm{UI} / \mathrm{g}): 20$; choline à $25 \mathrm{p}$. I00:20; vitamine A à 50000 II $/ \mathrm{g}$ : zo; vitamine $\mathrm{D}$ à I 00 ooo $\mathrm{UI} / \mathrm{g}): 2,5$; méthionine : roo; glucose $65 \mathrm{I}$.

(3) Mélange antibiotique pour I ooo $\mathrm{g}$ : terramycine à $80 \mathrm{p}$. I 000 : I $20 \mathrm{~g}$; spiramycine pure : Io $\mathrm{g}$; amidon : $870 \mathrm{~g}$.

renfermant 5 p. Ioo de lait écrémé sec (lot. I) ou Io p. Ioo de lactosérum doux sec ( $\operatorname{lot} 2$ ) ou bien 20 p. Ioo de ce même lactosérum (lot 3 ). Ces aliments étaient fournis ad libitum, sous forme de granulés de $2,5 \mathrm{~mm}$ de diamètre. Les quantités consommées étaient enregistrées chaque semaine par pesée des quantités offertes et refusées. Le transfert des couples de la porcherie d'élevage à celle d'engraissement a été effectué au cours de la neuvième semaine. A partir du poids vif de $20 \mathrm{~kg}$ les porcs ont été placés en loge individuelle. Douze portées ont été retenues et les 72 porcelets ont reçu des régimes à $\mathrm{I} 8 \mathrm{p}$. Ioo de protéines, différents par leur taux de lac- 
tosérum sec : o p. I oo (lot D); 30 p. I 00 (lot E); 60 p. Ioo (lot F) (tab1. 2). L'affectation a été faite de telle manière que les 9 traitements résultant de la combinaison factorielle des 3 régimes d'élevage et des 3 régimes de croissance soient représentés par quatre porcelets ( 2 femelles et 2 mâles castrés), selon une répartition en blocs incomplets.

A $60 \mathrm{~kg}$ de poids vif, chacun des 9 lots élémentaires a été subdivisé, 1'un des couples étant maintenu au régime de croissance à i 8 p. roo de protéines (lots $\mathrm{I}$, $\mathrm{E}, \mathrm{F})$ l'autre étant affecté à un régime de finition à I I p. roo de protéines (lots $\mathrm{A}$, B, C) (tabl. 2).

Les aliments d'engraissement ont été fournis sous forme de farine, humectée extemporanément, selon un mode de distribution semi ad libitum à raison de trois repas quotidiens de $20 \mathrm{mn}$ chacun. Les quantités consommées étaient en registrées journellement et l'eau fournie ad libitum, non contrôlée.

Les porcs ont été pesés individuellement chaque semaine et abattus lorsque leur poids vif atteignait au moins $95 \mathrm{~kg}$. Le sacrifice a été effectué à l'issue d'un jê̂ne de I 4 à I $6 \mathrm{~h}$. Après électro-narcose et saignée, le tube digestif a été prélevé pour des mesures d'activité enzymatique (FÉVRIER et AuMAITRE, 1979). Les carcasses ayant ressué $24 \mathrm{~h}$, les poids des différentes pièces, obtenues selon la découpe parisienne normalisée, ont été enregistrés.

Compte tenu du faible nombre d'animaux affecté à chaque traitement élémentaire, l'analyse statistique a été réalisée en confondant l'effet variation résiduelle et l'effet répétition. L'effet traitement a été décomposé en effets principaux et interactions (SNEDECOR et COCHRAN, 1967) et le seuil de probabilité de 0,025 a été retenu pour envisager une interprétation des différences observées comme n'étant pas dues au hasard. Un seuil de probabilité de 0,05 ne peut qu'indiquer des tendances qui mériteraient d'être contrôlées, surtout lorsqu'elles se rapportent à des interactions multiples.

Dans les tableaux et figures, les abbréviations suivantes ont été employées pour désigner les effets des traitements dans leur analyse statistique :

E1 : Effet linéaire du lactosérum dans le régime d'élevage.

Eq : Effet quadratique du lactosérum dans le régime d'élevage.

L1 : Effet linéaire du lactosérum dans le régime de croissance-finition.

Lq : Effet quadratique du lactosérum dans le régime de croissance-finition.

$P$ : Efftet du taux de protéines dans le régime de finition.

$S$ : Effet du sexe, mâles castrés ou femelles.

\section{Résultats}

\section{Porcelets en post-sevrage}

La période de post-sevrage a été décomposée en deux sous-périodes. La première, jusqu'à 63 jours, correspondait au maintien des animaux dans le local de naissance, à une température de 20 à $22{ }^{\circ} \mathrm{C}$. La seconde commençait le $64^{\mathrm{e}}$ jour par le transfert en porcherie d'engraissement non climatisée, à un poids variable selon les porcelets, entre I5 et $22 \mathrm{~kg}$ de poids vif (tabl. 3 ).

Jusqu'au $63^{\mathrm{e}}$ jour et par la suite jusqu'à $20 \mathrm{~kg}$ de poids vif, indépendamment du milieu, le régime à ıo $\mathrm{p}$. Ioo de lactosérum a permis une amélioration significative de la vitesse de croissance et de l'indice de consommation, grâce à une aug- 


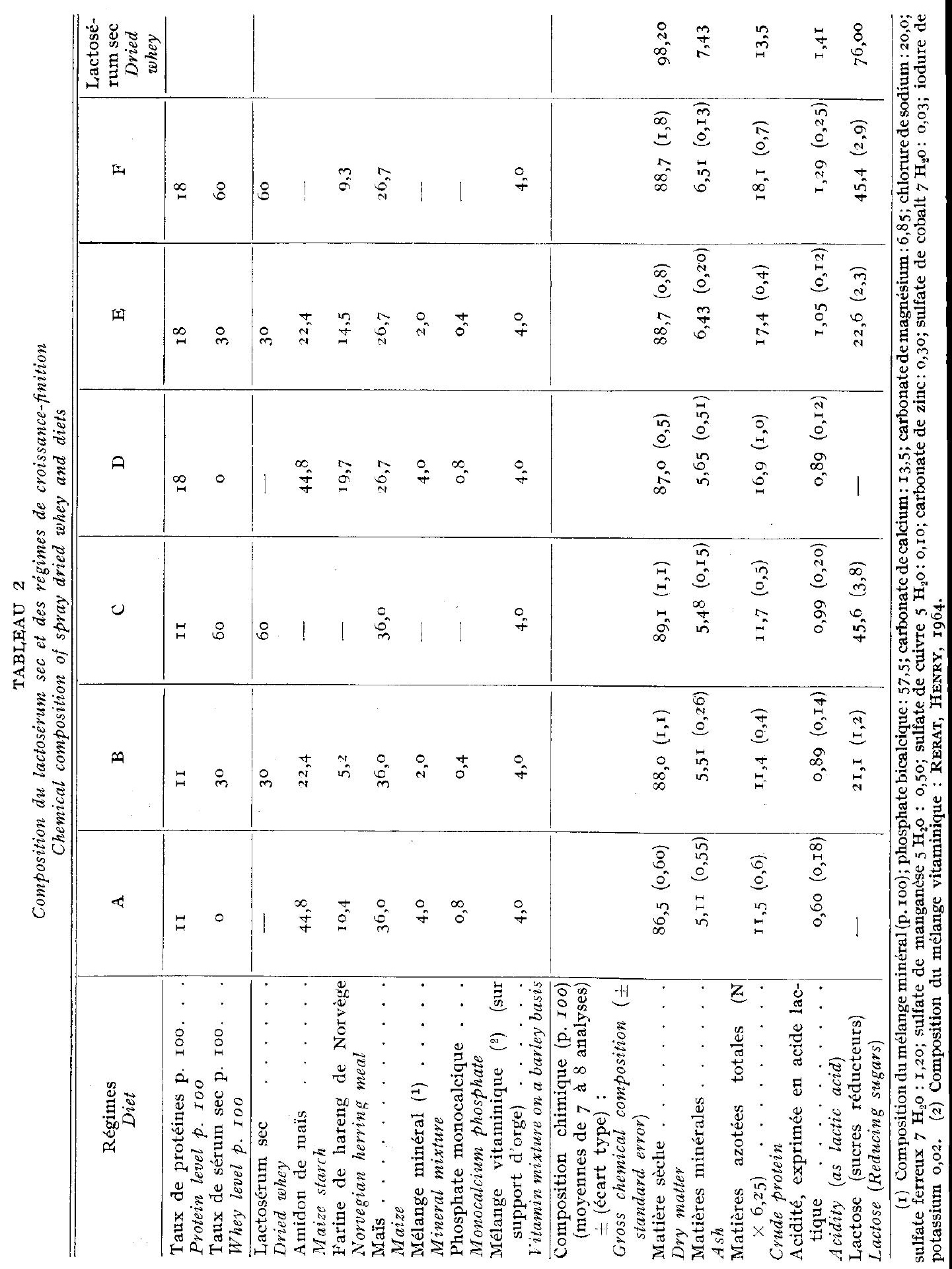




\section{TABI,EAU 3}

Résultats de croissance de 5 à 9 semaines d'âge et jusqu'au début de la période d'engraissement Average performance after weaning up to 63 days and $20 \mathrm{hg}$ of liveweight

Valeurs moyennes et écart type (s) (means and standard evror)

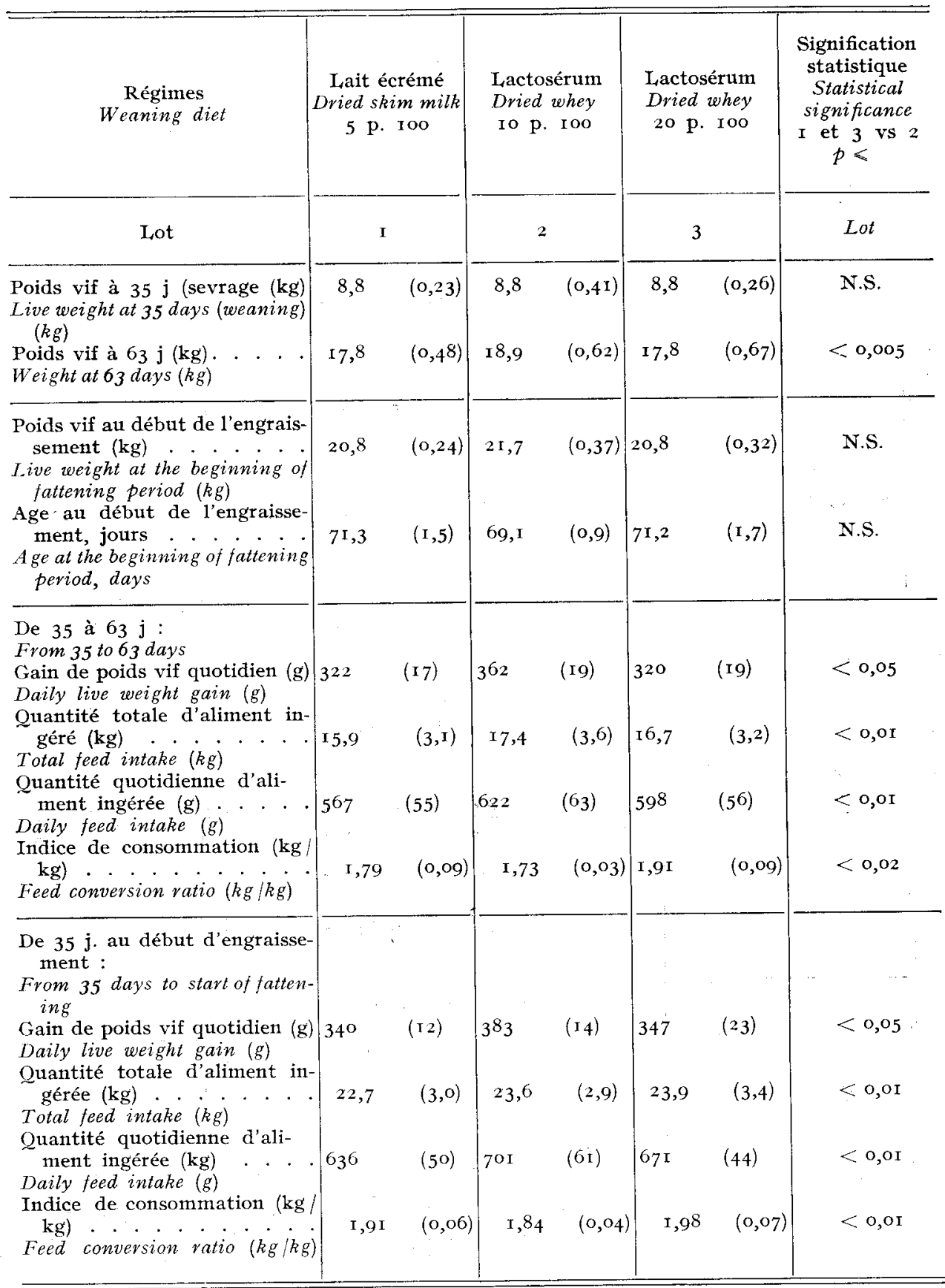




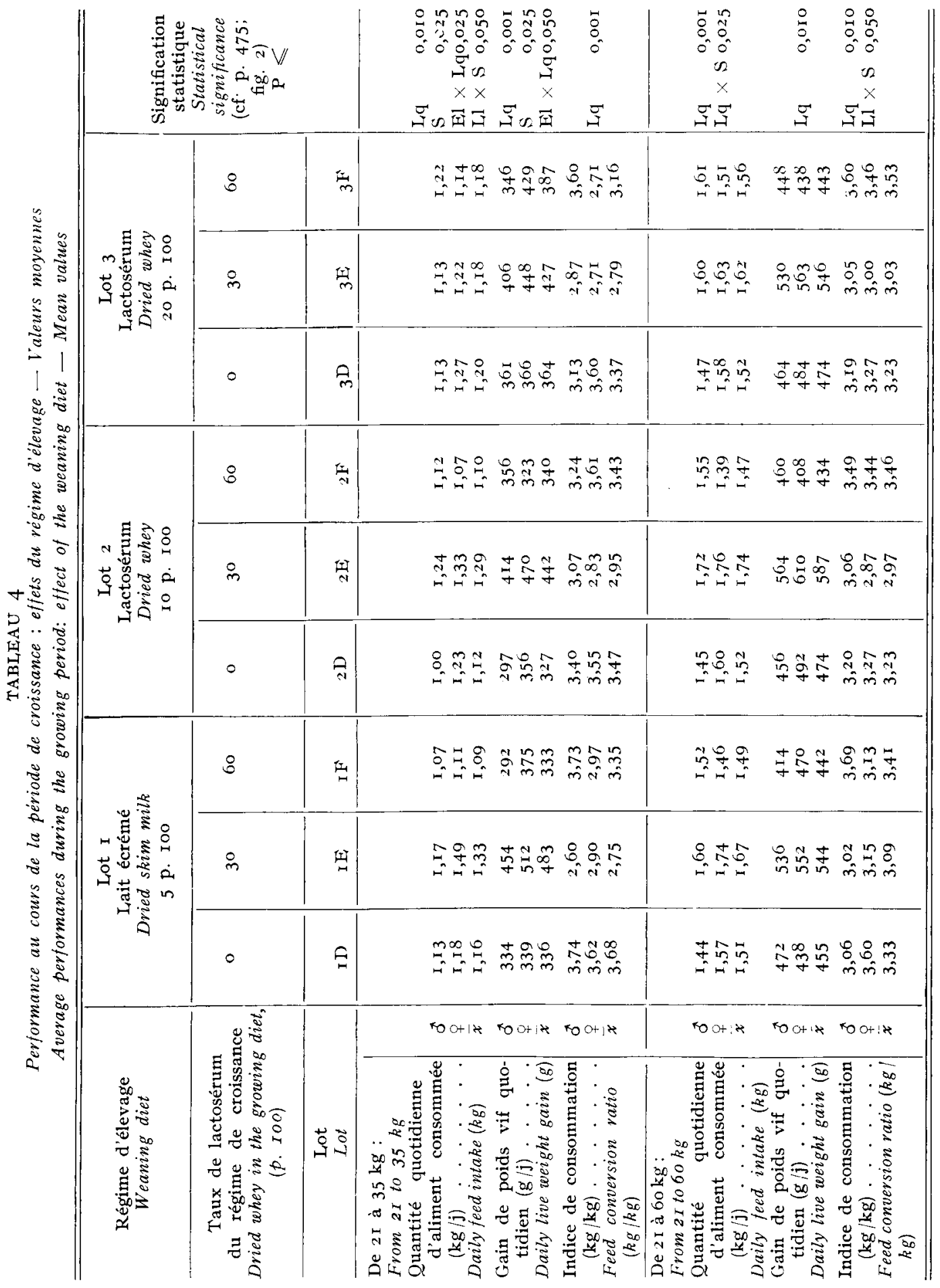


mentation hautement significative de la quantité quotidienne d'aliment consommée. En revanche, ce même lactosérum, employé à raison de 20 p. Ioo du régime n'a pas donné de résultats supérieurs à ceux du régime témoin à $5 \mathrm{p}$. Ioo de lait écrémé. On observe même une tendance à l'augmentation de l'indice de consommation au cours de la première phase après le sevrage $(+7 \mathrm{p}$. Ioo). Mâles castrés et femelles ont eu des performances équivalentes.

\section{Adaptation au régime de croissance}

L'adaptation proprement dite au régime de croissance s'est effectuée entre 2 I et $35 \mathrm{~kg}$ de poids vif, l'effet global du régime s'observant jusqu'à $60 \mathrm{~kg}$. Au cours des deux périodes (tabl. 4 et fig. 2) le régime à 30 p. Ioo de lactosérum sec a permis une croissance significativement supérieure à celle des autres régimes. Cependant il semblerait que ce soient surtout les porcelets issus du régime d'élevage à 5 p. Ioo de lait écrémé qui en aient le plus profité $(\mathrm{E} 1 \times \mathrm{L}, \mathrm{q}, p<0,025)$ et non pas ceux qui avaient déjà reçu un taux élevé de lactosérum, sauf peut être pour les mâles castrés qui ont consommé plus d'aliment que leurs homologues du lot témoin.

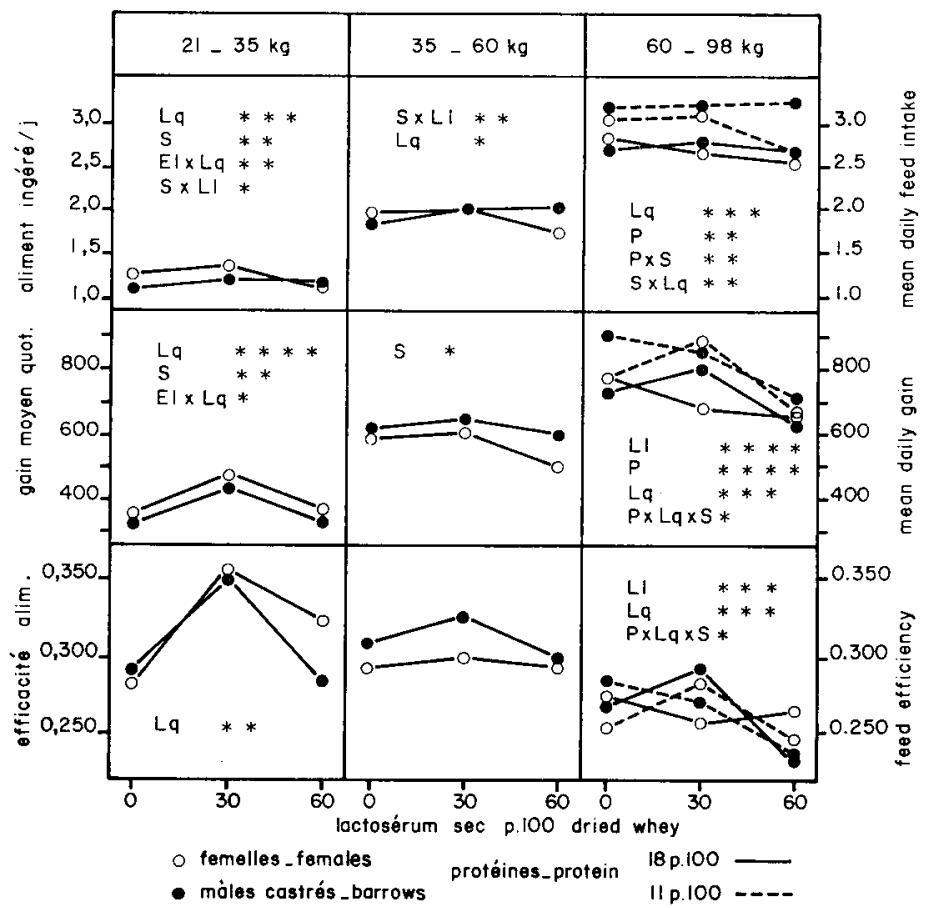

FIG. 2. - Performances moyennes au cours des trois principales périodes d'engraissement. Average performance during the three main periods of fattening

$\mathrm{El}$ : Linear effect of whey in weaning diet.

$\mathrm{Eq}$ : Quadratic effect of whey in weaning diet.

$\mathrm{L1}$ : Linear effect of whey in growing finishing diet.

$\mathrm{I}_{\mathrm{q}}$ : Quadratic effect of whey in growing-finishing diet.

$\mathrm{P}$ : Protein elfect in finishing diet.

$\mathrm{S}$ : Sex effect, castrated males or females. 
TABLEAU 5

Performances en cours de croissance-finition entre 20 et $98 \mathrm{~kg}$ de poids vif Average performance during the growing finishing period (20-98 $\mathrm{kg}$ live weight)

\begin{tabular}{|c|c|c|c|c|c|c|c|}
\hline \multirow{2}{*}{$\begin{array}{l}\text { Taux de lactosérum } \\
\text { en croissance finition } \\
\text { Dried whey in growing } \\
\text { finishing diets, } \\
\text { (p. Ioo) }\end{array}$} & \multirow{2}{*}{$\begin{array}{l}\text { Taux } \\
\text { de protéines } \\
\text { en finition } \\
\text { Proteins in } \\
\text { funishing diets } \\
\text { (p. IOO) }\end{array}$} & & \multicolumn{3}{|c|}{$\begin{array}{c}\text { Lots } I, 2,3, \\
\text { confondus } \\
I, 2,3 \text { confounded }\end{array}$} & \multicolumn{2}{|c|}{$\begin{array}{l}\text { Signification } \\
\text { statistique } \\
\text { Statistical } \\
\text { significance }\end{array}$} \\
\hline & & & $o$ & $3^{\circ}$ & 60 & (cf. p. $\begin{array}{l}475 \\
\\
\end{array}$ & ig. 2) \\
\hline $\begin{array}{c}\text { Quantité quotidienne d'aliment } \\
\text { consommé }(\mathrm{kg} / \mathrm{j}) \\
\text { Daily feed intake }(k g)\end{array}$ & I 8 & $\begin{array}{l}\frac{0}{0} \\
\frac{1}{x} \\
\frac{x}{x} \\
0 \\
0 \\
\frac{1}{x}\end{array}$ & $\begin{array}{l}1,92 \\
2,05 \\
1,99 \\
2,03 \\
2,10 \\
2,06\end{array}$ & $\begin{array}{l}2,08 \\
2,12 \\
2,10 \\
2,21 \\
2,27 \\
2,24\end{array}$ & $\begin{array}{l}1,97 \\
1,86 \\
1,91 \\
\\
2,12 \\
1,92 \\
2,02\end{array}$ & $\begin{array}{ll}\mathrm{Lq} & 0 \\
\mathrm{P} & \mathrm{o} \\
\mathrm{S} \times \mathrm{L} 1 & \mathrm{o}\end{array}$ & $\begin{array}{l}10 \\
50 \\
50\end{array}$ \\
\hline $\begin{array}{c}\text { Gain de poids vif quotidien } \\
(\mathrm{g} / \mathrm{j}) \\
\text { Daily live weight gain }(\mathrm{g} / \mathrm{j})\end{array}$ & I I & 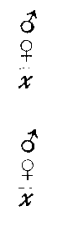 & $\begin{array}{l}575 \\
579 \\
575 \\
\\
595 \\
583 \\
589\end{array}$ & $\begin{array}{l}663 \\
632 \\
647 \\
646 \\
693 \\
670\end{array}$ & $\begin{array}{l}510 \\
517 \\
514 \\
542 \\
517 \\
530\end{array}$ & $\begin{array}{l}\mathrm{L} 1 \\
\mathrm{~L}, \mathrm{q} \\
\mathrm{S} \times \mathrm{L} 1 \times \mathrm{E} 1\end{array}$ & $\begin{array}{l}0,010 \\
0,001 \\
0,050\end{array}$ \\
\hline $\begin{array}{l}\text { Indice de consommation } \\
\quad(\mathrm{kg} / \mathrm{kg}) \\
\text { Feed conversion ratio }(\mathrm{kg} / \mathrm{kg})\end{array}$ & I 8 & $\begin{array}{l}0 \\
+ \\
+ \\
x \\
0 \\
0 \\
\frac{+}{x}\end{array}$ & $\begin{array}{l}3,36 \\
3,56 \\
3,46 \\
\\
3,42 \\
3,60 \\
3,5 \mathrm{I}\end{array}$ & $\begin{array}{l}3,17 \\
3,42 \\
3,39\end{array}$ & $\begin{array}{l}3,69 \\
3,59 \\
3,64 \\
\\
3,73 \\
3,74 \\
3,73\end{array}$ & N.S. & \\
\hline
\end{tabular}

Enfin les femelles ont eu une croissance légèrement supérieure à celle des mâles castrés $(402 \mathrm{~g} / \mathrm{j}$ contre $362 \mathrm{~g} / \mathrm{j})$. Mais ceci ne s'observe qu'au cours de la période d'adaptation, l'effet du régime d'élevage n'étant plus apparent à $60 \mathrm{~kg}$; seul persiste alors celui du taux intermédiaire de lactosérum qui procure aux femelles un indice de consommation plus favorable que celui des mâles castrés $(3,34$ contre 3,59). L'examen des résultats entre 35 et $60 \mathrm{~kg}$ (fig. 2) montre que les traitements appliqués ont été presque sans effet pendant cette période qui constituait, en quelque sorte, une étape de compensation préalable au changement d'aliment en période de finition.

\section{Incidence de la modification azotée en finition et résultats généraux}

Au cours de la période de finition de 60 à $98 \mathrm{~kg}$ (fig. 2), il est apparu que l'avantage apporté par l'incorporation de $30 \mathrm{p}$. Ioo de lactosérum sec perdait de son importance. De plus, à $60 \mathrm{p}$. Ioo il a entraîné une diminution hautement signi- 


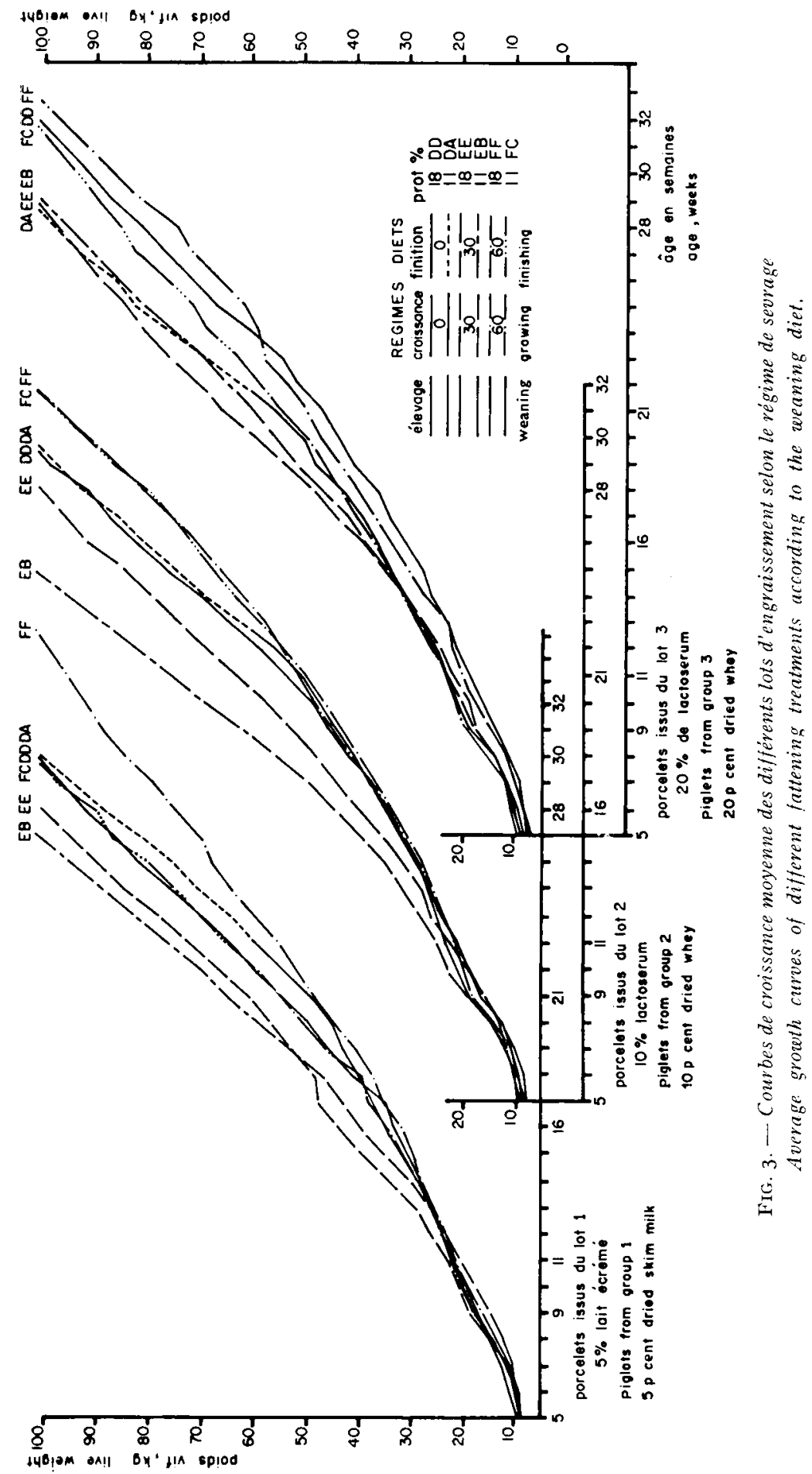


ficative de la vitesse de croissance et de l'efficacité alimentaire, alors que les quantités d'aliment ingérées étaient peu modifiées. En revanche la diminution du taux azoté a entraîné une augmentation de la quantité consommée et, corrélativement, de la vitesse de croissance, notamment avec les régimes contenant $30 \mathrm{p}$. Ioo de lactosérum, mais elle n'a pas eu d'effet significatif sur l'efficacité alimentaire.

En fin d'engraissement, un bilan général fait apparaître des effets significatifs sur la quantité d'aliment consommée, mais non sur l'efficacité alimentaire (tabl. 5). Ainsi, globalement, l'emploi de 30 p. Ioo de lactosérum dans la ration a permis une augmentation hautement significative de la vitesse de croissance, consécutive à une augmentation de la quantité d'aliment consommée. Ėn revanche, bien que les porcs témoins et ceux à 60 p. Ioo de sérum aient consommé la même quantité de matière sèche, la croissance des seconds a été significativement plus lente que celle des premiers.

Enfin, pour les animaux recevant $60 \mathrm{p}$. Ioo de lactosérum, la différence de vitesse de croissance entre les mâles castrés et les femelles était plus faible que pour les animaux témoins. Lorsque l'on observe les courbes de croissance, (gains de poids vif cumulés sur la figure 3 ), on remarque que les différences entre lots ne font que s'accentuer après $60 \mathrm{~kg}$ de poids vif. Toutefois, il semblerait que la variation de l'âge à l'abattage ait été légèrement plus faible lorsque les porcelet: ont été sevrés avec 20 p. roo de loctosérum.

TABI, EAU 6;

Caractéristique's des carcasses à l'abattage (98 $\mathrm{kg}$ de poids vif) Carcass characteristics at slaughter ( $98 \mathrm{~kg}$ of live weight)

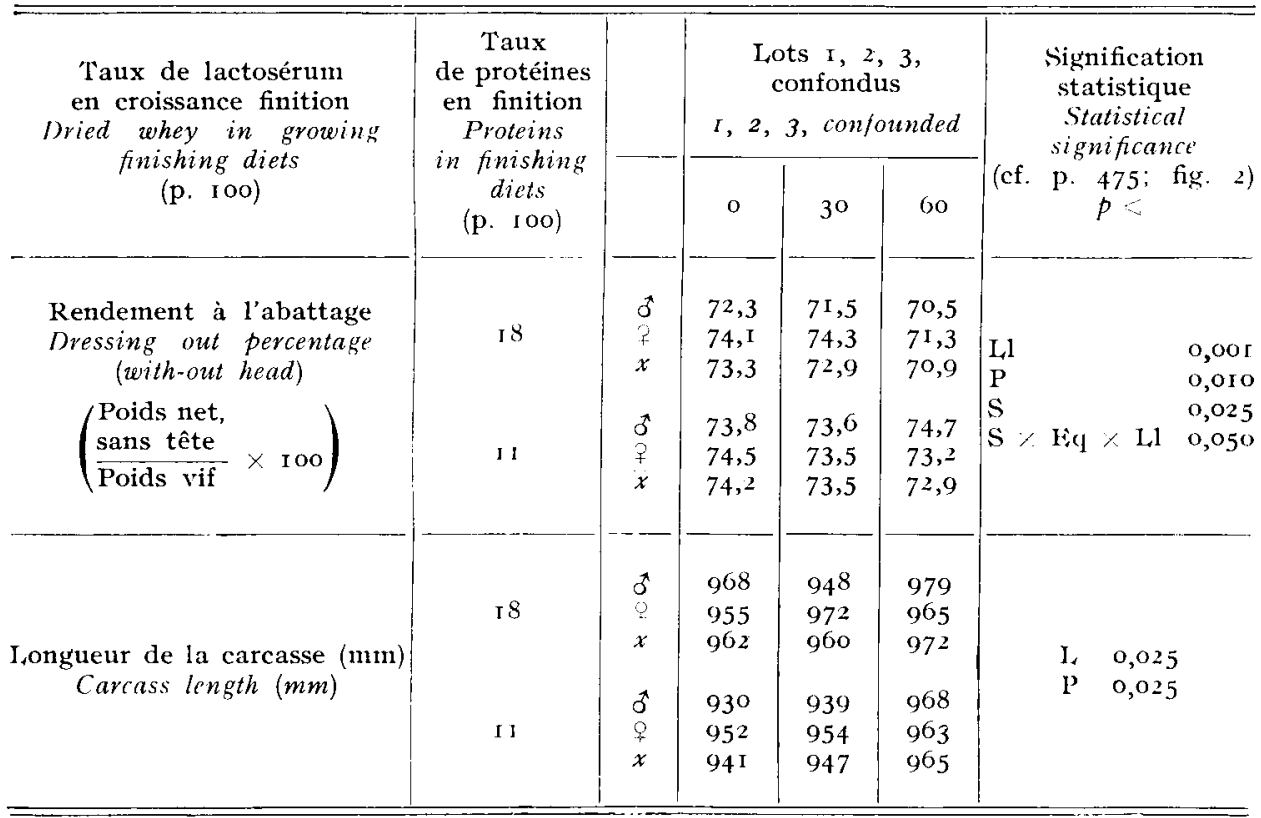




\section{Conséquences des modifications de régime sur la composition corporelle}

Le rendement à l'abattage (tabl. 6) a diminué à mesure que l'on augmentait le taux de lactosérum, de $73,7 \mathrm{p}$. Ioo pour les porcs témoins, à $7 \mathrm{r}, 9 \mathrm{p}$. Ioo pour ceux recevant 60 p. Ioo de sérum dans la ration. En revanche, il a augmenté lorsque le taux de protéine a été diminué au cours de la finition $(72,4$ p. Ioo contre 73,5 p. Ioo) et il est resté plus faible pour les mâles castrés que pour les femelles $(72,5$

\section{TABLEAU 7}

Composition des carcasses (98 $\mathrm{kg}$ de poids vif)

Carcass composition at slaughter ( $98 \mathrm{~kg}$ of live weight)

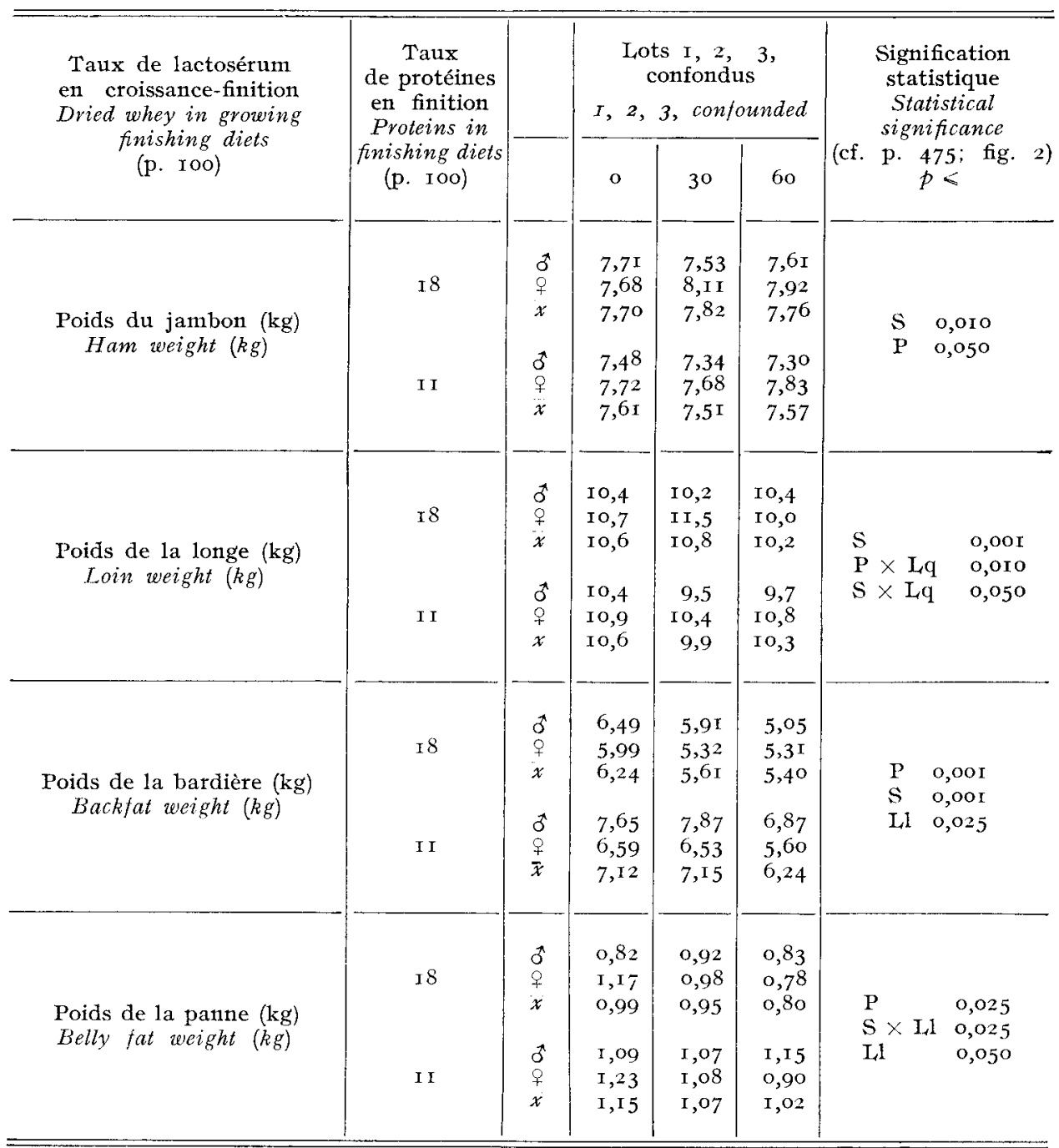


p. roo contre 73,5 p. I00). La longueur des carcasses a été augmentée par l'emploi de $60 \mathrm{p}$. Ioo de lactosérum $(968 \mathrm{~cm}$ contre $95 \mathrm{I} \mathrm{cm})$ et par l'augmentation du taux azoté ( 965 contre $95 \mathrm{I} \mathrm{cm}$ ).

Les poids des principales fractions caractéristiques de la carcasse (tabl. 7 ), ont été notablement modifiés par les variations de traitement alimentaire, mais le sexe a eu l'influence prépondérante. Ainsi les poids du jambon et de la longe des femelles étaient plus élevés que ceux des mâles castrés, (respectivement de 4,3 p. roo et de $3,9 \mathrm{p}$. Ioo) alors que le poids de leur bardière était plus faible de I2,2 p. roo. Cependant, alors que dans les lots témoins la panne des femelles était plus lourde que celle des mâles castrés (plus 24 p. Ioo), dans les lots recevant 60 p. Ioo de lactosérum elle était au contraire moins développée (moins 22,9 p. IOo). Le lactosérum n'a eu un effet important que sur les morceaux gras. Aussi le poids de la bardière a diminué de $4,5 \mathrm{p}$. Ioo puis de $\mathrm{I} 2,9$ avec respectivement 30 et $60 \mathrm{p}$. I 00 de lactosérum. Le poids de la panne diminuant dans les mêmes conditions de 7 puis de $\mathrm{I} 8,7 \mathrm{p}$. IOo. La diminution du taux de protéines dans le régime s'est traduite par une augmentation de l'état d'engraissement. Le poids de bardière a augmenté de I9,0 p. Ioo et celui de la panne de I7,6 p. Ioo, tandis que celui de la longe diminuait de $\mathrm{I}, 9 \mathrm{p}$. Ioo seulement. Cette dernière a présenté un poids minimum de $9,9 \mathrm{~kg}$ pour les porcs qui ont reçu 30 p. roo de lactosérum.

F́tant donné les variations simultanées du rendement à l'abattage et des poids des pièces découpées, ceux-ci ont été rapportés au poids net en groupant morceaux maigres d'une part, morceaux gras d'autre part (tab1. 8). Ceci con firme, avec plus de netteté, les effets prépondérants du taux azoté et du sexe, et plus modeste du

\section{TABIEAU 8}

Poids relatij des morcean maigres et gras, en pourcentage du poids net Carcass composition at slaughter (p. roo of the dressed carcass)

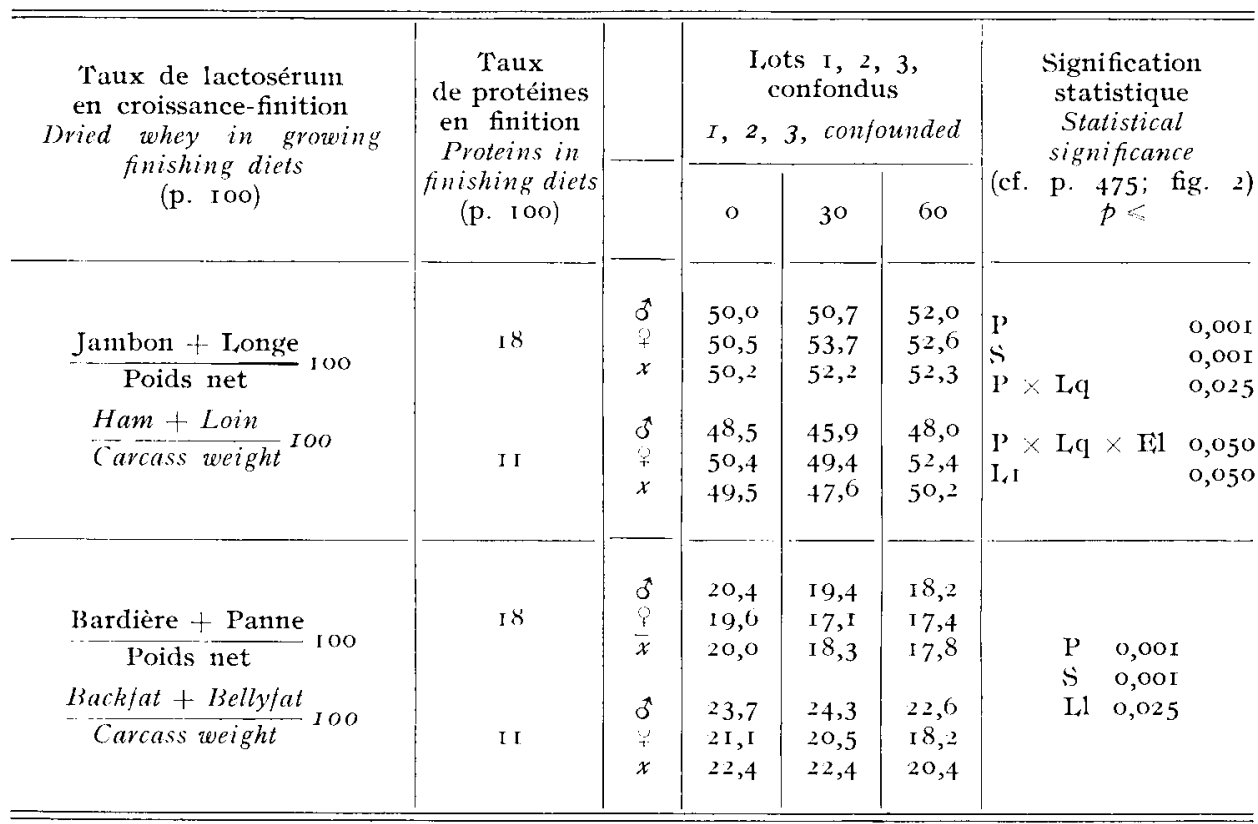


TABLEAU 9

Aspect qualitatif des carcasses

Average slaughter performance of animals (98 kg live weight)

\begin{tabular}{|c|c|c|c|c|c|c|c|}
\hline \multirow{2}{*}{$\begin{array}{l}\text { Taux de lactosérum } \\
\text { en croissance-finition } \\
\text { Level of whey in growing } \\
\text { finishing diets } \\
\text { (p. roo) }\end{array}$} & \multirow{2}{*}{$\begin{array}{l}\text { Taux } \\
\text { de protéines } \\
\text { en finition } \\
\text { Proteins in } \\
\text { finishing diets } \\
\text { (p. Ioo) }\end{array}$} & & \multicolumn{3}{|c|}{$\begin{array}{c}\text { Lots } \mathrm{I}, 2,3 \\
\text { confondus } \\
r, 2,3, \text { confounded }\end{array}$} & \multirow{2}{*}{\multicolumn{2}{|c|}{$\begin{array}{c}\text { Signification } \\
\text { statistique } \\
\text { Statistical } \\
\text { significance } \\
\text { (cf. p. } 475 ; \text { fig. 2) } \\
p \leqslant\end{array}$}} \\
\hline & & & o & 30 & 60 & & \\
\hline 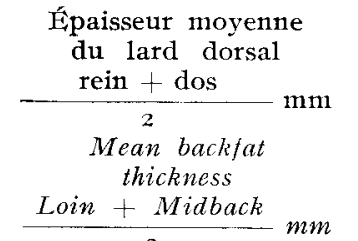 & 18 & $\begin{array}{l}0 \\
0 \\
+ \\
x \\
x \\
0 \\
0 \\
x \\
x\end{array}$ & $\begin{array}{l}3^{0,1} \\
3^{0,0} \\
3^{0,0} \\
34,2 \\
31,2 \\
3^{2,7}\end{array}$ & $\begin{array}{l}27,5 \\
26,5 \\
27,0 \\
\\
35,9 \\
30,6 \\
33,3\end{array}$ & $\begin{array}{l}28,1 \\
27,7 \\
27,9 \\
32,9 \\
27,4 \\
30,2\end{array}$ & 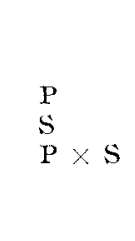 & $\begin{array}{l}0,010 \\
0,010 \\
0,025\end{array}$ \\
\hline $\begin{array}{l}\text { Rapport } \frac{\text { Longe }}{\text { Bardière }} \\
\text { Loin/Backfat ratio }\end{array}$ & I 8 & $\begin{array}{l}0 \\
+ \\
+ \\
x\end{array}$ & $\begin{array}{l}\mathrm{I}, 62 \\
\mathrm{I}, 80 \\
\mathrm{I}, 7 \mathrm{I} \\
\mathrm{I}, 37 \\
\mathrm{I}, 7 \mathrm{I} \\
\mathrm{I}, 54\end{array}$ & $\begin{array}{l}1,77 \\
2,34 \\
2,06 \\
\\
1,22 \\
1,64 \\
1,43\end{array}$ & $\begin{array}{l}\mathrm{I}, 90 \\
\mathrm{I}, 99 \\
\mathrm{I}, 95 \\
\mathrm{I}, 43 \\
\mathrm{I}, 95 \\
\mathrm{I}, 7 \mathrm{O}\end{array}$ & $\begin{array}{l}\mathrm{P} \\
\mathrm{P}\end{array} \times \mathrm{Lq}$ & $\begin{array}{l}0,00 I \\
0,00 I \\
0,050\end{array}$ \\
\hline $\begin{array}{l}\text { Qualité de la viande } \\
\text { Note de o à } 5 \\
\text { Meat quality } \\
(5 \text { Best o Worst })\end{array}$ & 18 & $\begin{array}{l}0 \\
0 \\
+ \\
x \\
0 \\
0 \\
0 \\
\frac{1}{x}\end{array}$ & $\begin{array}{l}\mathrm{I}, 83 \\
\mathrm{r}, 83 \\
\mathrm{I}, 83\end{array}$ & $\begin{array}{l}1,83 \\
2,67 \\
2,25 \\
I, 83 \\
1,83 \\
\mathrm{I}, 83\end{array}$ & $\begin{array}{l}2,17 \\
2,67 \\
2,42 \\
2,33 \\
1,83 \\
2,08\end{array}$ & $\begin{array}{lll}\mathrm{L} 1 & 0\end{array}$ & 025 \\
\hline
\end{tabular}

lactosérum sur la diminution d'adiposité. Le rapport Longe/Bardière (tabl. 9) les précise avec une mention particulière pour les porcs, recevant $30 \mathrm{p}$. Ioo de lactosérum sec et II p. Ioo de protéines, chez lesquels l'état d'engraissement a été significativement plus élevé que chez tous les autres animaux. Ces effets se retrouvent également sur l'épaisseur du lard dorsal. Enfin, en aucun cas le régime de sevrage ne s'est traduit par un effet quelconque sur la qualité de la carcasse.

La qualité de la viande a été jugée selon les critères habituels de couleur, exsudativité, tenue, etc... et noté de o à 5 de la plus mauvaise à la meilleure (tabl. 9). Elle est assez médiocre compte tenu des conditions d'abattage (transport avant abattage, non repos, prélèvement immédiat des viscères avant échaudage, non refroidissement des carcasses). Mais dans ces conditions, ce sont les lots recevant du lactosérum qui ont présenté la moins mauvaise qualité de viande. 


\section{Influence du lactosérum sur l'état sanitaire}

Le lactosérum et le lactose ayant la réputation de provoquer des diarrhées importantes chez le porc, celles-ci ont été observées quotidiennement depuis l'âge de 35 jours. A partir de $2 \mathrm{r} \mathrm{kg}$ on a distingué trois états diarrhéiques (visuel-

TABLEAU 10

Fréquence moyenne des diarrhées

Average scouring frequency for piglets and growing-finishing pigs

\begin{tabular}{|c|c|c|c|c|c|c|c|c|c|c|c|}
\hline \multirow{2}{*}{\multicolumn{3}{|c|}{ 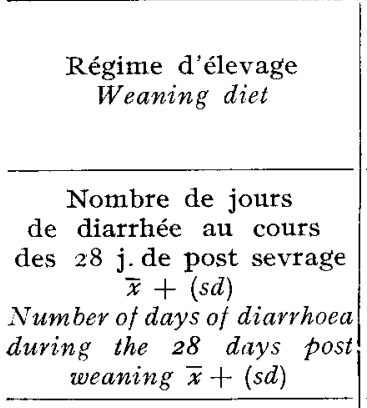 }} & \multicolumn{3}{|c|}{$\begin{array}{l}\text { I } \\
\text { Lait écrémé } \\
\text { Dried skim milk } \\
5 \text { p. Ioo }\end{array}$} & \multicolumn{3}{|c|}{$\begin{array}{l}2 \\
\text { Lactosérum } \\
\text { Dried whey } \\
\text { Io p. Ioo }\end{array}$} & \multicolumn{3}{|c|}{$\begin{array}{l}3 \\
\text { Lactosérum } \\
\text { Dried whey } \\
20 \text { p. Ioo }\end{array}$} \\
\hline & & & \multicolumn{3}{|c|}{$\begin{array}{c}7,72 \\
(5,88)\end{array}$} & \multicolumn{3}{|c|}{$\begin{array}{c}5,00 \\
(3,00)\end{array}$} & \multicolumn{3}{|c|}{$\begin{array}{c}3,86 \\
(3,62)\end{array}$} \\
\hline \multicolumn{3}{|c|}{$\begin{array}{l}\text { Régime d'engraissement } \\
\text { Fattening diet } \\
\text { Sérum sec (p. Iоo) } \\
\text { Dried whey (p. Ioo) }\end{array}$} & 0 & 30 & 60 & $o$ & $3^{\circ}$ & 60 & $o$ & $3^{\circ}$ & 60 \\
\hline \multirow{3}{*}{$\begin{array}{c}\text { Nombre } \\
\text { de jours } \\
\text { de diarrhée } \\
\text { pour Ioo j. } \\
\text { d'engrais- } \\
\text { sement } \\
\text { Number } \\
\text { of days of } \\
\text { diarrhoea } \\
\text { for } \\
\text { Ioo days } \\
\text { of fattening }\end{array}$} & $\begin{array}{c}\text { Protéines } \\
\text { (p. Ioo) } \\
\text { Proteinsin } \\
\text { finishing } \\
\text { diet } \\
\text { I8 }\end{array}$ & $\begin{array}{l}x \\
0 \\
o \\
x\end{array}$ & $\begin{array}{r}\mathrm{I}, \mathrm{O} \\
\mathrm{I} 5,0 \\
8,0 \\
\\
6,0 \\
\mathrm{I}, 5 \\
3,7\end{array}$ & $\begin{array}{r}\mathrm{I0}, \mathrm{O} \\
6,5 \\
8,2 \\
\mathrm{I} \\
\mathrm{I}, \mathrm{O} \\
7,0 \\
9,0\end{array}$ & $\begin{array}{l}45,0 \\
42,5 \\
43,7 \\
51,5 \\
22,0 \\
36,7\end{array}$ & $\begin{array}{l}6,5 \\
6,5 \\
6,5 \\
6,0 \\
2,5 \\
4,2\end{array}$ & $\begin{array}{r}\mathrm{I} 9, \mathrm{O} \\
4,0 \\
\mathrm{II}, 5 \\
\mathrm{r} \\
\mathrm{r} 0,5 \\
7,5 \\
9, \mathrm{O}\end{array}$ & $\begin{array}{l}28,0 \\
34,0 \\
31,0 \\
\\
36,0 \\
11,5 \\
23,7\end{array}$ & $\begin{array}{r}15,0 \\
5,0 \\
10,0 \\
\\
8,0 \\
3,0 \\
5,5\end{array}$ & $\begin{array}{r}17,5 \\
8,5 \\
13,0 \\
17,0 \\
13,0 \\
15,0\end{array}$ & $\begin{array}{l}35,0 \\
20,0 \\
27,5 \\
\\
39,5 \\
15,5 \\
27,5\end{array}$ \\
\hline & & & \multicolumn{6}{|c|}{$\begin{array}{l}\text { Lots } 1,2,3 \text { confondus } \\
\quad 1,2,3 \text { confounded }\end{array}$} & \multicolumn{3}{|c|}{$\begin{array}{c}\text { Signification } \\
\text { statistique } \\
\text { Statistical signiflcance } \\
\text { (cf. p. } 475 \text {; fig. } 2 \text { ) } \\
\mathrm{P} \leqslant\end{array}$} \\
\hline & I 8 & $\begin{array}{l}x \\
0 \\
q \\
-x\end{array}$ & \multicolumn{2}{|c|}{$\begin{array}{l}7,5 \\
8,8 \\
8,2\end{array}$} & \multicolumn{2}{|c|}{$\begin{array}{r}\text { I } 5,5 \\
6,3 \\
x 0,9\end{array}$} & \multicolumn{2}{|c|}{$\begin{array}{l}3^{6,0} \\
3^{2}, 2 \\
34,1\end{array}$} & \multicolumn{3}{|c|}{$\begin{array}{ll}\mathrm{L1} 1 & 0,00 \mathrm{I} \\
\mathrm{Lq} & 0,010 \\
\mathrm{~S} & 0,010 \\
\mathrm{~S} \times \mathrm{LI} & 0,05^{\circ}\end{array}$} \\
\hline
\end{tabular}


et une baisse de rendement des presses; les granulés particulièrement durs sont peu appétibles pour le porcelet. Moyennant une addition de graisse et un savoir-faire particulier on peut cependant en augmenter le taux jusqu'à 34 p. Ioo dans un aliment de sevrage à Io jours (SEVE, FÉvrier et Aumaitre, I975) et son utilisation est aussi satisfaisante que celle d'aliment ne contenant que du lait écrémé. Selon BECKER et al. (I957) les porcelets de I4 jours peuvent utiliser convenablement des régimes non granulés comportant jusqu'à $60 \mathrm{p}$. Ioo de sérum sec. Avec des porcelets de 3 semaines, KorNEGAY, Thomas et KRAMER (I974) obtiennent une amélioration des performances avec I 7,5 p. roo de lactosérum sec. En revanche, WAHLSTROM, HAUSER et I.IBAL (I974) employant du lactosérum partiellement délactosé (50 p. Ioo de lactose) pour des porcelets de 5 semaines trouvent une diminution des performances, accompagnée d'un effet diarrhéique important. Enfin, après 9 semaines comme dans la présente expérience, les porcelets recevant des aliments non granulés peuvent encore valoriser des régimes renfermant plus de 30 p. Ioo de sérum (Hanrahan, I97I). Chez le jeune, les troubles nutritionnels tels que les diarrhées ne semblent pas directement liés au lactose (WAHLSTrom, HAUSER et LIBAL, I974; ENTRINGER et al., 1975) mais peut être davantage à 1'équilibre minéral ou à la qualité microbiologique du lactosérum. Chez les porcelets en bonne santé, l'utilisation digestive n'est pas modifiée par l'emploi du lactosérum ou du lactose (Seve, FÉvrier et Aumaitre, r975; Baird, Cromwell et Hays, I976); en revanche elle est diminuée lorsque la diarrhée apparaît (ENTRINGER et al., 1975).

En conclusion, la limite à l'emploi de lactosérum sec dans les aliments pour porcelets, quel que soit l'âge au sevrage, est donc bien d'ordre technologique (dureté des granulés, débit économique des presses). Incorporé jusqu'à $30 \mathrm{p}$. Ioo, il peut être une excellente source glucidique pour le porcelet, tout en apportant des protéines de qualité.

\section{2. - Utilisation du lactosérum sec par le porc en croissance-finition}

Pour le porc à l'engrais, recevant l'aliment en farine humectée, le taux moyen optimum est de $30 \mathrm{p}$. Ioo de la ration. Il n'est pas nécessaire d'insister sur ce point parfaitement acquis (BECKER et al., r957; BRAUDE et al., I957; DUNKIn, I963; Hanrahan, I97I; Ekstrom, Benevenga et Grummer, I975a; FÉvrier, I978) mais plutôt d'observer les nuances et les variations de réponse en fonction du régime de sevrage, de l'âge et de la nature de la complémentation.

L'adaptation au régime de croissance contenant des proportions élevées de lactosérum sec ne s'est pas mieux réalisée pour les porcelets ayant eu un régime de post-sevrage à $20 \mathrm{p}$. Ioo de lactosérum et ceci est en accord avec des résultats d'Ekstrom, Benevenga et Grummer (I975b). Paradoxalement le lactosérum a été légèrement bénéfique pour les porcelets n'ayant reçu que $5 \mathrm{p}$. Ioo de lait écrémé. Mais cet effet en début de croissance est très transitoire car, dès $60 \mathrm{~kg}$ de poids vif, ces différences minimes sont compensées, ainsi que 1'ont également observé KoRNEGAY, Thomas et Kramer (I974). En revanche, si l'adaptation précoce au lactosérum ne semble pas nécessaire, il apparaît que le niveau optimum, ou maximum, compatible avec une croissance et une efficacité alimentaire convenables tend à diminuer avec l'âge. Fintre $2 \mathrm{I}$ et $35 \mathrm{~kg}$, les porcelets ont pu en effet tirer profit des régimes contenant $60 \mathrm{p}$. Ioo de sérum sec, à égalité avec le régime témoin. Les régimes à $30 \mathrm{p}$. Ioo de lactosérum ont toutefois permis les résultats les plus favorables; au delà de $35 \mathrm{~kg}$, ils ne donnent plus de performances nettement supérieures à celles du témoin et au delà de $60 \mathrm{~kg}$, ils se révèlent déjà légèrement dépressifs. 
L'emploi de bo p. Ioo de lactosérum sec est excessif dès que les porcs dépassent le poids de $60 \mathrm{~kg}$. Cette évolution, déjà observée par DunkIN (I957) et SHEARER et DUNKin (I968), est à mettre au compte de 1'utilisation digestive et métabolique du lactose puisque la quantité de lactase disponible n'augmente plus que lentement après 8 semaines (MANNERs et Stevens, I972; TACu et RöMer, I973;; Eikstrom, Benevenga et Grummer, i975 $b$ et $c$; Aumattre et Corring, I978). Dans ces conditions, la quantité de lactose non hydrolysé augmente et fournit un substrat à une flore intestinale lactique dont le développement se traduit par une hypertrophie du caecum et du côlon (ShEarer et DUNkIN, I968; FÉvrier, Collét et Bourdon, I973; FÉvrier, I978; FÉvrier et Aumaitre, I978). Les produits terminaux de la fermentation, acide lactique, acides gras volatils (FrIEND, Cunninghan et Nicholson, ig63; Kim, Benevenga et Grummer, i976; CleMENS, STEVENS et SOUTHWORTh, I975; Rerat et al., I977) sont bien utilisés par le porc (Charlet. Lery, I965; WhitTAKers, Cranweli et Johnston, I974) bien que d'une valeur énergétique nette inférieure à celle de l'amidon (JENTSCH, SchIEMANN et Hofrman, I969). L'emploi de quantités importantes de lactosérum en période de finition se traduit donc par une restriction énergétique, qui ne peut pas être compensée par un niveau d'alimentation plus élevé en raison d'une limite de l'appétibilité de l'aliment.

\section{3. - Conséquences de l'alimentation au lactosérum sur la qualité des carcasses}

La restriction du niveau énergétique chez les porcs recevant de grandes quantités de lactosérum explique pour une part la diminution d'état d'engraissement et du rendement à l'abattage. Mais pour ce dernier une autre cause en est l'augmentation du poids du tractus digestif. Les effets les plus importants sur la qualité des carcasses, en accord avec les résultats classiques, sont dus au sexe (DESMoulin et Bourdon, I97I) et à l'apport azoté (HENRY et Bourdon, I976). Toutefois, les porcs soumis, en finition, au régime à $30 \mathrm{p}$. Ioo de lactosérum et II p. Ioo de protéines ont été anormalement gras.

Ceci peut s'expliquer en terme d'équilibre azote-énergie. La quantité de lysine qu'ils ont ingérée n'était en effet que de $20 \mathrm{p}$. Ioo supérieure aux besoins et celle d'acides aminés soufrés de io p. Ioo inférieure aux besoins, alors que chez les porcs témoins ces quantités étaient respectivement de roo p. Ioo et $30 \mathrm{p}$. Ioo supérieure aux besoins. Par ailleurs, le niveau de consommation d'énergie était supérieur de I3 p. Ioo à celui des animaux témoins. Cet effet du faible taux azoté sur l'adiposité des carcasses est moins évident chez les porcs recevant $60 \mathrm{p}$. roo de lactosérum en raison d'une part de la plus mauvaise utilisation énergétique du lactose, de la diminution de la vitesse de croissance et de l'effet favorable du lactose sur la rétention azotée (FÉvrier, données non publiées; RERat et Bourdon, I974), bien que ce glucide à haute dose tende à diminuer la digestibilité des matières azotées (EinTrinGER et al., I975; BAIRD, CROMWELL et HAYS, I976; FÉVRIER, données non publiées). Ces effets pourraient également expliquer la meilleure qualité de carcasse des porcs recevant $30 \mathrm{p}$. Ioo de lactosérum et I $8 \mathrm{p}$. Ioo de protéines.

\section{4. - Lactosérum et état sanitaire}

L'augmentation de la fréquence des diarrhées due à un excès protéique n'est pas apparue en cours d'engraissement mais le lactosérum, particulièrement au taux le plus élevé, a eu un effet très important. Toutefois, on sait maintenaint que le lactose n'en est pas directement responsable (EnTringér et al., I975; Février, 
données non publiées), contrairement à ce qui avait été avancé par WHITTIER, CARY et Eilis (I935) et SHEARER et DUNKIN (I968). L'équilibre minéral est plus probablement en cause. La teneur en minéraux des régimes à 60 p. Ioo de sérum sec était supérieure de $7 \mathrm{p}$. Ioo ou de $\mathrm{I} 5 \mathrm{p}$. roo à celle des régimes témoins, au taux respectifs de I I et I $8 \mathrm{p}$. Ioo de protéines. La fréquence des diarrhées est moins grande chez les femelles que chez les castrats, peut-être en raison d'un niveau de consommation moins élevé (moins 8 p. Ioo) mais aussi d'une meilleure utilisation énergétique du lactose. Nos données ne nous permettent pas toutefois de conclure.

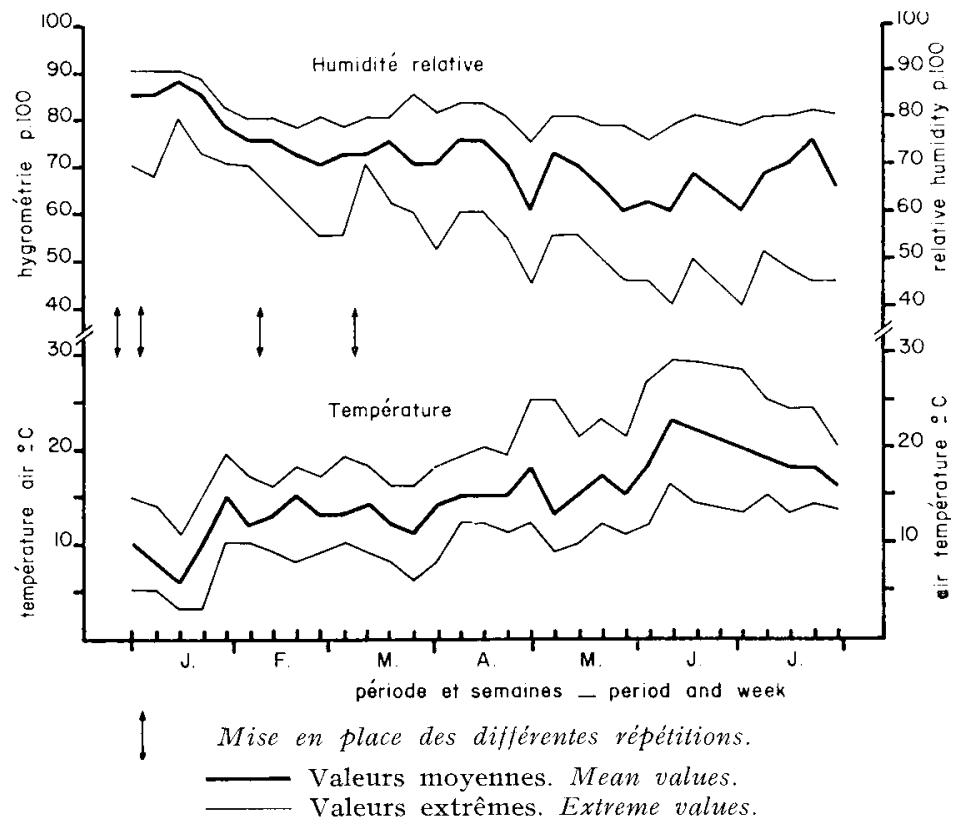

FIG. 5. - Conditions climatiques durant l'engraissement Climatic conditions during the fattening period

Une certaine relation entre l'intensité et la fréquence des diarrhées et les conditions microclimatiques de la porcherie est rapportée dans la figure 5. E1le montre que durant les 3 premiers mois de l'expérience la température moyenne de l'air était inférieure à $15{ }^{\circ} \mathrm{C}$ et l'humidité relative supérieure à $70 \mathrm{p}$. Ioo pour des animaux devant consommer naturellement de plus grandes quantités d'eau que d'ordinaire (FÉVRIER, I966). Dans ce cas l'emploi du lactosérum a pu être un facteur prédisposant et même déterminant de l'apparition des diarrhées, en accord avec les observations de Holmes (I97I) sur l'interaction entre l'effet du milieu et l'alimentation au lactosérum.

\section{Conclusions}

On peut donc conclure, après cette nouvelle expérience que la valeur d'utilisation du lactosérum sec décroit à mesure que le porc croît. Du sevrage à l'abattage à Ioo $\mathrm{kg}$ de poids vif, le taux moyen optimal de lactosérum sec correspond, en accord avec tous les expérimentateurs antérieurs à environ un tiers de la ration 
sèche. Toutefois, si cette proportion permet un gain d'efficacité alimentaire très important chez le porcelet nourrain, elle donne après $60 \mathrm{~kg}$ de poids vif, des résultats juste équivalents à ceux obtenus avec un régime dépourvu de lactosérum.

Puisque l'utilisation de régimes riches en lactose ne semble être défavorable qu'en fin d'engraissement, il n'est pas surprenant qu'une tentative d'adaptation à l'emploi du lactose par une fourniture constante de celui-ci après le sevrage se révèle inefficace. Par ailleurs, pour une utilisation rationnelle, le lactosérum nécessite une complémentation protéique adaptée, sans excès, mais respectant l'apport en acides aminés, selon les besoins particuliers en fonction du sexe.

Dans les conditions européennes actuelles, le séchage du lactosérum en vue de son incorporation dans d'autres aliments que ceux d'allaitement artificiel est trop coûteux pour être d'une utilisation pratique et courante. Toutefois, l'extrapolation des présents résultats aux conditions d'emploi du lactosérum natif permet les remarques suivantes. Dans des conditions encore habituelles de l'élevage au lactosérum où l'on suit les capacités d'ingestion d'eau du porc, la proportion de matière sèche de lactosérum croît au même rythme que le poids du porc. Ceci constitue donc une erreur sur le plan nutritionnel, puisque la valeur alimentaire de la ration ne peut que diminuer. Ces résultats permettent également de penser que l'emploi du lactosérum concentré (à partir de $150 \mathrm{~g} / 1$ ) serait plus rationnel car il permettrait de constituer alors plus de $50 \mathrm{p}$. Ioo de la matière sèche de la ration dès le sevrage, tout en limitant la proportion à 30 p. Ioo en période de finition.

Accepté pour publication en avril 1978.

\author{
Summary \\ Use of dried whey in pig feeding \\ II. - Adaptation and consequences on growth and feed conversion
}

The adaptation of growing-finishing pigs to the supply of large amount of lactose in their diets from weaning was studied in 72 Large White pigs ( 36 females and 36 castrated males) weaned at 35 days. Thirty six couples of piglets from I 2 litters were fed with three weaning diets (pellets) containing 5 p. Ioo dried skim milk (group I) or Io p. Ioo (group 2) or 20 p. Ioo (group 3) dried sweet whey. From $20 \mathrm{~kg}$ live weight, the piglets of each group were alloted, according to a factorial design, to three growing diets (moist meal) containing i 8 p. Ioo protein and o p. roo (group D), 30 p. Ioo (group E) and $60 \mathrm{p}$. Ioo (group F) dried whey. From $60 \mathrm{~kg}$ live weight half of the animals were fed a diet including only i $p$. roo protein and with the same level of dried whey (groups A, B, C) (fig. I, tabl. I and 2 ).

After weaning, at $8.8 \mathrm{~kg}$ liveweight and until $2 \mathrm{I} \mathrm{kg}$, the best performance was obtained with the diet containing ro p. Ioo dried whey (group 2, table 3). With $20 \mathrm{p}$. roo whey the pellets were harder and less palatable, but the results were not different from those obtained with the control pigs. After $2 \mathrm{I} \mathrm{kg}$, the diets containing $30 \mathrm{p}$. Ioo dried whey gave the best growth per formance up to $60 \mathrm{~kg}$ live weight. Whereas the results obtained with those containing $60 \mathrm{p}$. I 00 dried whey not significantly differ from those of the controls until $35 \mathrm{~kg}$ live weight (fig. 2 ). However, the pigs fed with the $20 \mathrm{p}$. I 100 whey in weaning diets did not valorise the $60 \mathrm{p}$. I 00 whey in fattening diets better than the controls pig. Accordingly, a continuous or early supply of lactose does not lead to subsequent adaptation to the use of this carbohydrate. After $60 \mathrm{~kg}$ live weight the results recorded with $3^{\circ} \mathrm{p}$. I 00 of whey were not better than those obtained in the controls, whereas the $60 \mathrm{p}$. Ioo whey diets had a depressive effect. Lowering of the protein level brought about an increase in feed intake and accordingly in the growth rate (fig. 2). For the whole growing period (20-100 kg) (tabl. 5) the most satisfactory results were obtained with 3o p. roo dried whey. The higher growth rate of castrated males as compared to females was more marked with the control diets than with those including whey. The female carcasses were 
leaner than those or castrated males. A reduction of fatness was also obtained by increasing the whey level during the finishing period. However the difference in carcass composition between females and castrated males was larger in the control animals than in those receiving dried whey. The carcasses of pigs receiving $3^{\circ} \mathrm{p}$. I oo whey and I I p. Ioo protein during the finishing period were abnormally fat. The results can be explained by the decrease in the energy yield when using a large proportion of lactose during the finishing period. This decrease is due to the intestinal fermentations of lactose given in excess relatively to the hydrolysis ability of intestinal lactase.

Accordingly the amino-acid/net energy ratio is changed by decreasing the yield of metabolisable energy. Furthermore, the diets containing lactose (especially with $60 \mathrm{p}$. Ioo) have an important diarrheic effect, more marked in castrated males than in females.

The best valorisation of whey is obtained by using moderate amount during the finishing period ( $\mathrm{I} / 3$ of the ration) and adequately supplemented without any excess of protein and in account of the particular requirements depending on sex.

\section{Références bibliographiques}

Aherne F. X., Hays V. W., Ewan R. C., Speer V. C., 1969. Absorption and utilization of sugars by the baby pigs. J. Anim. Sci., 29, 444-450.

Aumairre, A., Corring T., 1978. Development of digestive enzymes in the piglet from birth to 8 weeks. II. Intestine and intestinal disacharidases. Nutr. Metab., 22, 244-255.

Batrd J. R., Cromwei, G. L., Hays V. W., I976. Fiffect of dried whey and lactose on performance and nutrient digestibility in pigs and chicks. J. Anim. Sci., 43, 249. (Abstr.)

BECKER D. E., ULI,REY D. C., TERRILL S. W., I954a. Comparison of carbohydrates in synthetic milk for the baby pig. Arch. Biochim. Biophys., 48, I78-183.

BECKER D. E., ULLREY D. E., TERRIL S. W., I954b. Various carbohydrates in a semi-purified diet for the growing pig. Arch. Biochim. Biophys., 50, 399-404.

BeCKER D. E., TERRIL S. W., Jensen A. H., HENSON L. J., I957. High levels of dried whey powder in the diet of swine. J. Anim. Sci., 16, 404-4Iz.

Bolin T. D., MC KERN A., Davis A. E., 1971. The effect of diet on lactase activity in the rat. Gastroenterology, 57, 406-409.

BOzKOWA K., BARDOŃ A., I973. Activity of disaccharidases in the small intestine of rats during growth and the effect of diet. Problemy Medycyny Wieku Rozwojowego, 3, 119-125 in Nutr. Abstr. Rev., 45, (2070).

Braude R., Clarke P. M., Mitchelil K. G., Cray A. S., Franke A., Sedgwick P. H., 1957. Unrestricted whey for fattening pigs. J. Agric. Sci., 49, 347-356.

CHARLET-LERY G., I965. Utilization of the energy of lactic acid by growing pigs: a comparison with starch. In BLAXTER K. L. Energy Metabolism, 279-284 (Academic press inc. (London)).

Ci,EMENS E. T., STEvens C. E., Southworth M., 1975. Sites of organic acid production and pattern of digesta movement in the gastrointestinal tract in swine. J. Nutr., 105, 759-768.

Desmoulin B., BouRdon D., I97I. La séparation des pores mâles castrés et des pores femelles en alimentation restreinte depuis le sevrage : I. Réponse de croissance et d'efficacité nutritionnelle. Journées rech. Porcine en France. Paris, I.N.R.A.-I.T.P. éd., 3, 73-80.

Dunkin A. C., 1957. Whey for fattening pigs. Proc. N.Z. Soc. anim. Prod., 17, 1.95, 37-40.

DUNKIN A. C., 1963. Lactic casein whey powder in rations for pigs. I. - - The substitution of un-neutralized lactic casein whey powder for barley meal in an all-meal ration for growing pigs. J. Dairy Res., 30, 323-330.

DUNKIN A. C. 1963. Lactic casein whey powder in rations for pigs. II. - A comparison of un-neutralized and neutralized lactic casein whey powders with barley in an all-meal ration for growing pigs. J. Dairy Res., 30, 33 I-338.

EKSTROM K. E., BENEVENGA N. J., GRUMMER R. H., 1975a. Effects of various dietary levels of dried whey on the performance of growing pigs. J. Nutr., 105, 846-850.

Ekstrom K. E., Benevenga N. J., Grummer R. H., 1975b. Effects of diets containing dried whey on the lactase activity of the small intestinal mucosa and the content of the small intestine and caecum of the pig. $J$. Nutv., 105, $85 \mathrm{I}-860$. 
Ekstrom K. E., Benevenga N. J., Grummer R. H., I975c. Changes in the intestinal lactase activity in the small intestine of two breeds of swine from birth to 6 weeks of age. J.Nutr., 105, $1032-1038$.

Entringer R. P., Plumlee M. P., Conrad J. H., Cline T. R., Wolfe S., i975. Influence of diet on passage rate and apparent digestibility by growing swine. J. Anim. Sci., 40, $486-494$.

FÉVRIER C., I966. Interrelations entre la composition du régime et la consommation d'eau chez le porc à l'engrais. $9^{\circ}$ Congrès International de Zootechnie, Edimbourg.

FÉvrier C., 1978. Lactosérum sec dans l'alimentation du Porc. I. Interaction avec le taux azoté du régime selon le stade de croissance et le sexe. Ann. Zootech., 27, 195-210.

Février C., Aumaitre A., r979. Lactosérum sec dans l'alimentation du Porc. III. Conséquences sur l'activité de la lactase intestinale et de l'amylase pancréatique. Ann. Zootech., 28 (I) (in press).

Fúvrier C., Colret J., Bourdon D., I973. Utilisation de divers types de lactosérum dans les régimes de sevrage des porcelets et durant la période de croissance finition. Journées Rech. Porcine en France. Paris, I.N.R.A.-I.T.P., éd., 5, $79^{-86 .}$

FISHER J. E., 1957. Effects of feeding a diet containing lactose upon $\beta$-D-galactosidase activity and organ development in the rat digestive tract. Amer. J.Physiol., 188, 49-53.

Friend D. W., Cunningham H. M., Nichoison J. W. G., ig63. The production of organic acids in the pig. II. The effect of diet on the levels of volatil acids and lactic acid in sections of alimentary tract. Canad. J. Anim. Sci., 43, I 56-168.

HanRahan T. J., I97I. Whey solids in the diet of growing finishing pigs. I. Dried whey as a feed for pigs. Ir. J. Agvic. Res., 10, I-7.

HENRY Y., Bourdon D., I 976 . Influences respectives de l'équilibre en acides aminés et du taux azoté sur les performances du porc en croissance. Journées rech. Porcine en France. Paris, I.N.R.A.-I.T.P., éd., 8, 37-42.

Holmes C. W., 1971. Growth of pigs feed cool whey at two ambiant temperatures. Anim. Prod., 13, I-6.

Jentsch W., SchimmanN R., Hofrman I., I969. Utilization of the energy of ethanol, acetic acid and lactic acid in trials with pigs. In BLAXTER K. L., KIELANOvSKI J., ThORBEK G. Energy metabolism of farm animals, 319-322. Oriel Press Ltd. Newcastle.

KIM K. I., BENEVENGA N. J., GRUMmer R. H., I976. Lactose fermentation in the cecum and colon of pig. J. Anim. Sci, 42, I350. Abstr. no 49.

KORNEGAy E. T., ThOMAS H. R., KRAMER C. Y., I974. Evaluation of protein levels and milk products for pig starter diets. J. Anim. Sci., 39, 527-535.

Manne,s M. J., Stevens J. A., I972. Changes from birth to maturity in the pattern of distribution of lactase and sucrase activity in the mucosa of the small intestine of pigs. Brit. $J$. Nutr., 28, I $13-137$.

Peo E. R. Jr., I964. The pig starter. An engraved calling card. Feed Age, 14, 30-34.

Pion R., Fauconneau G., I 966 . Les acides aminés des protéines alimentaires. Méthodes de dosage et résultats obtenus. Amino-acides, Peptides, Protéines Cahier no 6 AEC. Société de chimie organique et biologique. Commentry.

Rerat A., Aumaitre A., Vaissade, P., VAugerade P., r977. Étude expérimentale qualitative de l'absorption des glúcides après ingestion d'un repas à base de lactose. Ann. Biol. anim. Bioch. Biophys., 17, 589-596.

RERA'T A., Bourdon D., I974. Valeur nutritive de l'urée comme source d'azote indifférencié en présence ou non de lactose chez le porc en croissance finition. Journées Rech. Porcine en France. Paris, I.N.R.A.-I.T.P. éd., 6, I $75^{-1} 85$.

RERAT A., HENRY Y., I 964 . Utilisation de la betterave danoise dans l'alimentation du porc en croissance. I. - Recherche d'un plan de rationnement. Ann. Zootech., 13, 2 I 7-236.

Seve B., Fŕvrier C., Aumaitre A., 1975. Alimentation glucidique du porcelet sevré à 10 jours. Effets du lactose, de 1'ultrafiltrat de lactosérum et de la maltodextrine sur les performances des porcelets et 1'utilisation des régimes. Journées Rech. Porcine en France. Paris; I.N.R.A.I.T.P. éd., 7, I6I-I 67.

Sewell R. F., WEST J. P., 1965. Some effects of lactose on protein utilization in the baby pig. J. Anim, Sci, 24, 239-24I.

Shearer I. J., DUNkIN A. C., I968. Lactose utilization by the growing pig. N.Z.J.Agric. Res., 11, 465-476.

Shearer I. J., DUNkin A. C., 1968. Caecum enlargment in the lactose-fed pig. N.Z.J.Agric. Sci., 11, 923-926.

Snedicor G. W., Cochran W. G., 1967. Statistical methods, 6th Ed. The Iowa State University Press. Ames Iowa, U.S.A. 
TACU A., RömER D., 1973. L'activité lactasique de l'intestin et du pancréas chez les porcins (Roumain). Lucr. stiint. Inst. Cercet. Nutr. Anim., 1, zo9-229.

Wahlstrom R. C., HaUSER L. A., Libal G. W., i974. Effects of low lactose whey, skim milk and sugar on diet palatability and performance of early weaned pig. $J$. Anim. Sci., 38, 1 267$127 \mathrm{x}$.

Wen C. P., A. N. Tonowicz I., Tovar E., Mc Gavoy R. P., Gershoff S. N., I973. Lactose feeding in lactose intolerant monkeys. Amer. Clin. Nutr., 26, I224-I 228.

Whittakers A., Cranwel, P. D., Johnston G., 1974. Utilization of fermentation products in the baby pig. Proc. Austr. Soc. Anim. Prod., 10, 394.

Whittier E. O., Caky C. A., Elilis N. P., r935. The effects of lactose on growth and longevity, $J$. Nutr., 9, 52 I-53I. 